\title{
Investment Decision Based on Value Factor and Financial Criteria- Taking Apple Inc. as Analysis Sample
}

\author{
Zehua Zhang \\ University of Science and Technology, Hefei, Anhui, China \\ angela@cas-harbour.org
}

Keywords: Value Investment, Financial Criteria, PE Ratio, Time-Series, Investing Strategy.

\begin{abstract}
Value investment is an important method of stock selection. It is crucial to effectively select the value stock when conducting fundamental analysis and analyzing financial ratios. This article takes Apple Inc. as an example of a case study and proposes value factor improvement and selection in time-series: split value factor (PE ratio as a case study) based on mean reversion, and analyzes the main source of profit as core profit based on data of 10-K. Then more analysis of value factors and fundamental indexes are documented to get a summary of the holding strategy in short term. In the second part, the author conducts a time-series analysis and draws a conclusion as the following: poor performance of $\mathrm{PE}$ in the long term is primarily due to the high market expectation.
\end{abstract}

\section{Introduction}

The concept of "value investment" was initially proposed by Benjamin Graham and David Dodd in the book named Securities Analysis (1934), and later, thanks to Warren Buffett's research and practice, the value investment was increasingly popular with investors. The empirical research on value investment has been carried out enthusiastically to explore market effectiveness and asset return. Fama and French (1992) divided sample stocks based on BM (book to market value ratio) and EP (net profit to price ratio), the value factors, by using NYSE, AMEX, NYSE databases between 1963 and 1990. It has been found that the group with large BM and EP value can obtain higher excess return rate compared to other groups, and the excess return is the form of compensation for risk has been verified[1]. Researchers often classify stocks with high BM or EP ratios as value stocks in finance. Abarbanell and Bushee (1997) proved that the value investment strategy could generate higher excess returns based on the UK stock exchanges analysis[2]. Chui and Wei (1998) studied Asian stock markets for the first time and found that the correlation between the average return of shares and the beta coefficient was not obvious, but the correlation with BM was greater[3]. Wang et al. (2012) found that the stock portfolio with large EP index can obtain positive excess return based on the A-share sample data of 2003-2009, also proving the effectiveness of EP as an investment value index[4].

Value investment is one of the most effective investment strategies, and fundamental analysis can help comprehend a variety of profit and price from the firm and the market's level. Lev (1993) set up 12 financial indicators and found that these financial indicators are all related to the current earnings of the company[5]. Abarbanell and Bushee (1997) verified return improved nearly 13.2\% when conducting investment on the basis of these 12 indexes[2]. Lu Xuan (2001) analyzed the annual report of A-share in China and proved that the information of the sample companies provided in the financial report is helpful to forecast the future profit from both qualitative and quantitative perspectives[6].

There are also many previous studies based on both fundamental information and value evaluation. Yao Hui (2014) verified that optimal excess returns can be obtained by taking into account both fundamental and valuation factors and that the effect of medium and long-term holding increases profit rate[7]. Therefore, based on the previous research of China's securities market and the current information of academic research, with particular reference to the central ideas of value investment, this article measures investment strategy by taking into account both the 
fundamental criteria and value factors. Only stocks with good fundamental performance and relatively low-value ratio can gain stable excess returns.

The IT industry is one of the most dynamic areas of the national economy and is one of the most popular industries among investors. IT companies are subordinate to high-tech enterprises with the following characteristics: 1 . Intangible assets account for a large proportion of total assets, and the knowledge and intelligence are dominated competitiveness; 2. High technology makes updated products rapidly; 3. Technological innovation and leadership are maintained and enhanced by expensive research; 4. The investment of IT industry has high risk and return. Most of the risks are technical risks. For example, the loss caused by technical failure in the product development, the market systematic risk determined by whether technological innovation could gain the necessary market share during the pre-investment period, the incidence of financial crises depends on whether technological innovation can be recovered at the early stage of investing and obtain the expected profit; 5. The company grows quickly. Although the initial scale of management was small, the IT enterprises can improve competitiveness by virtue of high-tech innovation to realize rapid development in short term.

Apple Inc. is a US company and a leader in the IT industry with well-known innovation in hightech and electronic technology products. In spite of its industrial success, the investment value of Apple Inc. requires further determination based on fundamental analysis and financial criteria. I selected six factors, including value factor and value-growth rate ratio as references to conduct a comparable analysis among three IT companies. I recorded calculation of financial criteria from growth, profitability, operations, liabilities, and liquidity perspective of the Apple Inc. for fundamental analysis. I draw a conclusion of holding strategy in short term. Furthermore, the timeseries of trend analysis in PE, specifically EPS, free cash flow and close price was conducted. I made a different suggestion with the result of the cross-section by recommending short strategy in the long run.

\section{Cross-sectional investment value analysis}

\subsection{Value factor mean reversion}

In their research, U-In Kok and Jason Ribando documented the facts that "value investment" strategy does not involve the intrinsic value of underlying security and the simple value ratios (such as net market capitalization) does not effectively identify the undervalued stocks that frequently miscalculated by the market[8]. Instead, they often screen out companies with temporarily bright accounting figures. For example, the BM ratio as stock selection factor usually screened out the companies without sustainable high profits. The forward earnings to market ratio are often screened by companies that are overly optimistic about profitability by researchers.

Besides, they verified mean reversion of three fundamental-to-price ratios (book-to-market ratio, trailing-earnings-to-price ratio, and forward-earnings-to-price ratio, respectively). Based on the analysis of literary readings, ratio is split to find high value component:

$$
\mathrm{Ft}+1 / \mathrm{Pt}+1=(\mathrm{Ft} / \mathrm{Pt})(\mathrm{Ft}+1 / \mathrm{Ft})(\mathrm{Pt} / \mathrm{Pt}+1)
$$

Where Ft and $\mathrm{Pt}$ are the fundamental variables and price to the time-series value at time $\mathrm{t}$, rearranged in Daniel and Titman's work (2006)[9], the natural logarithms of variables in Eq.(1) is taken:

$$
\log (\mathrm{Ft}+1 / \mathrm{Pt}+1)=\log (\mathrm{Ft} / \mathrm{Pt})+\log (\mathrm{Ft}+1 / \mathrm{Ft})-\log (\mathrm{Pt}+1 / \mathrm{Pt})
$$

Ending Ratio $=$ Beginning Ratio + Change in Fundamental - Change in Price

The above three ratios confirmed with mean reversion have been calculated. For the sake of observation, the price-to-fundamental ratio is analyzed instead of using the original value. The left column of each panel corresponds to the difference of initial value ratio of the stock with the average value ratio. The middle two columns represent the contribution of the accounting data change and the price change, and the right column is the difference of final value ratio of the stock with the average value ratio, as shown in Figure1. 
The figure identifies the drivers of mean reversion in log price-to-fundamental ratio. The data source of three bars is retrieved from the www.sec.gov and www.estimize.com. The close prices of Apple Inc. are available from the CRSP database.

Drivers of Reversion in Log Trailing P/E

Ratio

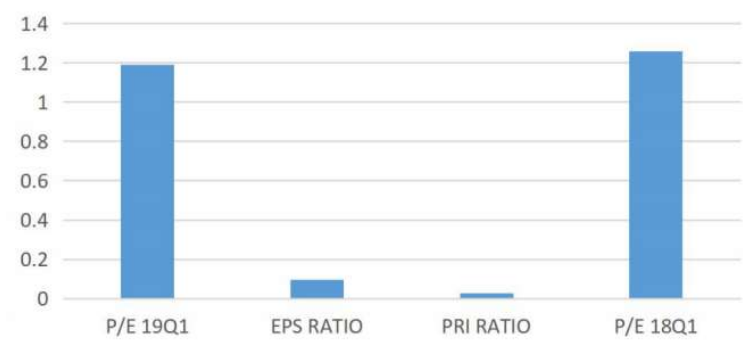

Panel A: Trailing Price-to-Earnings
Drivers of Reversion in Log Forward P/E Ratio

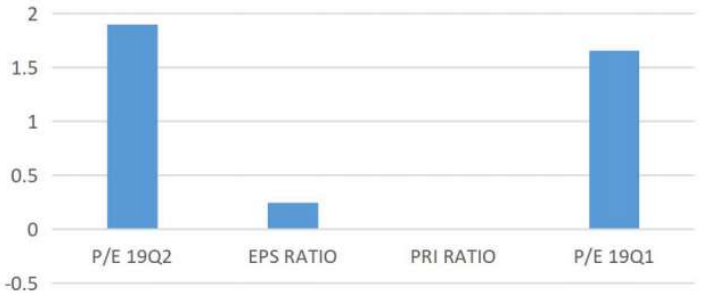

Panel B: Forward Price-to-Earnings

Drivers of Reversion in Log Trailing P/B

Ratio

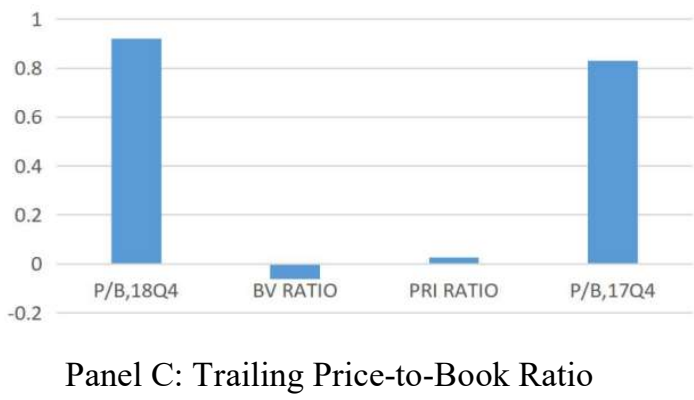

Figure1. The first bar shows the trailing annual ratio from the first quarter of 2018 to 2019, and the following bar shows the quarterly data of forward Price-to-Earning ratio in 2019. The third bar shows the drivers of reversion of book-tomarket ratio in the last quarter from 2017 to 2018.

After clarifying the existence of the mean reversion of the value ratio, the capital gains whether brought by the price change need to be further determined during investment. It shows that the left column in panel $\mathrm{A}$ is shorter than the right column, indicating a mean reversion because of difference decline with the increase of time between the real-time PE ratio and average PE ratio of Apple Inc.'s stock. In the middle of each bar in three Panels, the price change impact and even partial mean reversion offset are contrasted to the large proportion of accounting data (PE, PB, etc.) during exploring reversion drivers. Therefore, a simple analysis of some value ratio (such as net market rate) does not effectively identify stocks misestimated by the market, resulting in value indicator improvement and diversity in demand when building investment strategies. In the following section, this paper decomposes the price-to-earnings ratio to analyze drivers' variety.

\subsection{Decomposition}

The PE ratio is a comprehensive indicator in which long-term investors can determine the reverse of stock return and short-term investors can observe the level of stock prices. As one of the most common and necessary indicators in value investment analysis, the PE ratio is the ratio of stock market price divided by earnings per share, similar to the concept of "static investment payback". It reflects the company's performance and stock investment value to a certain degree. However, there are several shortcomings exists: 1) the PE ratio does not reflect the source and composition of profits, such as rising profits due to price adjustment; 2) the PE ratio displays statically crosssectional performance at historical point.

Drawing on the uncertainty of profit source for the PE ratio, this article introduces a different procedure for decomposing earning per share into core profit per share and occasional profit per share. The core profit is the company's income from the main business and long-run investment income related to the main business minus the cost, taxes, and various expenses. The company's 
income from other investment, subsidy, and operating expenses are occasional profits. It is shown in Eq. 3 and Figure2.

$$
\mathrm{Ft}=\mathrm{Fct}+\mathrm{Fot}
$$

\section{Proportion of Profit}

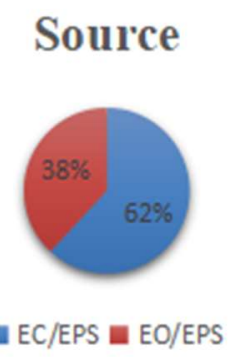

Figure 2. The proportion of core profit per share and occasional profit per share to EPS in 2018

The higher core profit per share and the less occasional profit per share indicate the main distinct business, the competitiveness of the leading product market, large sustainable development potential, and valuable long-term investment return. The opposition means that the larger proportion of total profits comes from non-recurring income and only shows that the company is fortunate enough to eat the pie in the sky, which could lead to whitewashed profits. The higher occasional profit cannot be a signal of sustainable operation and strong profitability. As seen in Figure 2, the less occasional profit with a relatively large proportion can rule out the speculation that the profit may be unstable in the future. The specific performance requires the introduction of more factors and time series trend analysis for reference.

\subsection{Combination of value factor and financial criteria}

Based on the result of verifying the mean reversion of price-to-fundamental ratio and the decomposition of EPS, it can be concluded that the PE ratio, which is the most elementary factor in value investment, cannot work in making an investment decision and trading strategy and should be considered from more dimensions. Therefore, more cross-sectional factors have been introduced, including other valuation indicators and financial criteria.

\subsubsection{Value factors}

The PE ratio is one of the most commonly used indicators to assess whether stock price levels are reasonable, as mentioned before. The PE score can show the value of the stock, specifically, 0-13: value is underestimated; 14-20: normal level; 21-28: value is overvalued; over 28: reflects speculative bubble in the stock market. Similarly, The loIr PB and PS ratio predict the higher investment return. The loIr PB contributes to loIr risk and higher possibility of stocks undervalued theoretically. The stock with a PS ratio greater than 10 needs to be firmly thrown and can be sighed in holding position when less than 1 . The value-growth rate ratio is one of the most effective ways to comprehensively examine value and growth. For example, the PEG focuses on the company's growth and is suitable for finding stocks with low PE relative to high growth rates. The ideal PEG value should in the range between 0.5 and 1 , and the stock is more likely be overvalued when PEG is greater than 1, the same situation happens to the PB-EPS growth rate and PS-sales growth rate. The stock selection index system combining low PE, PB, PS ratio and relatively higher valuegrowth rate ratio can obtain obvious excess returns.

The basic financial data of each time point cannot be obtained when calculating the valuation indicators and financial criteria. Each factor is calculated by the latest data published in 10-K. When analyzing the valuation factors, the negative index of the stocks will be eliminated and an integrated method will be adopted to determine the financial growth factor with the following formula in order to avoid the problem of the previous negative value and positive growth rate of the current period. The growth rate $=$ (current attribute - previous attribute) $/$ abs (previous attribute). The current value indicators are calculated by using the latest four quarters based on $10-\mathrm{K}$ revealed in SEC. The definition and value of each value factors are shown in Table 1. 
Table1. Cross-sectional value factors of Apple Inc.

\begin{tabular}{|c|c|c|c|}
\hline Dimension & Value Indicators & Definition & Value \\
\hline \multirow{4}{*}{ Value } & PE & Market profit ratio & 12.59 \\
\cline { 2 - 4 } & PEG & $\begin{array}{c}\text { PE ratio relative to earning per share growth } \\
\text { ratio }\end{array}$ & 7.29 \\
\cline { 2 - 4 } & PS & Market sales ratio & 2.88 \\
\cline { 2 - 4 } & PB & Market book value ratio & 5.22 \\
\cline { 2 - 4 } & PB-EPS growth rate & $\begin{array}{c}\text { PB ratio relative to earning per share growth } \\
\text { ratio }\end{array}$ & 3.021 \\
\cline { 2 - 4 } & PS-sales growth rate & PS ratio relative to sales growth ratio & - \\
\hline
\end{tabular}

Given the static characteristic of the value factors, the meaning of the cross-sectional value of a single company is limited, so I conducted a comparable analysis based on three IT companies, the remaining two companies are Western Digital and 3D Systems. The Western Digital Corporation (WDC) engages in the manufacture, market, and sale of data storage devices and solutions. The company offers mobile drives for the notebook, gaming markets, serial attached small computer system interface drives, peripheral component interconnect express SSDs, home network storage devices, personal cloud storage, etc. 3D Systems Corporation (DDD) is a holding company engages in the provision of comprehensive three-dimensional printing solutions. It includes threedimensional printers, materials, software, on-demand manufacturing services, and digital design tools.

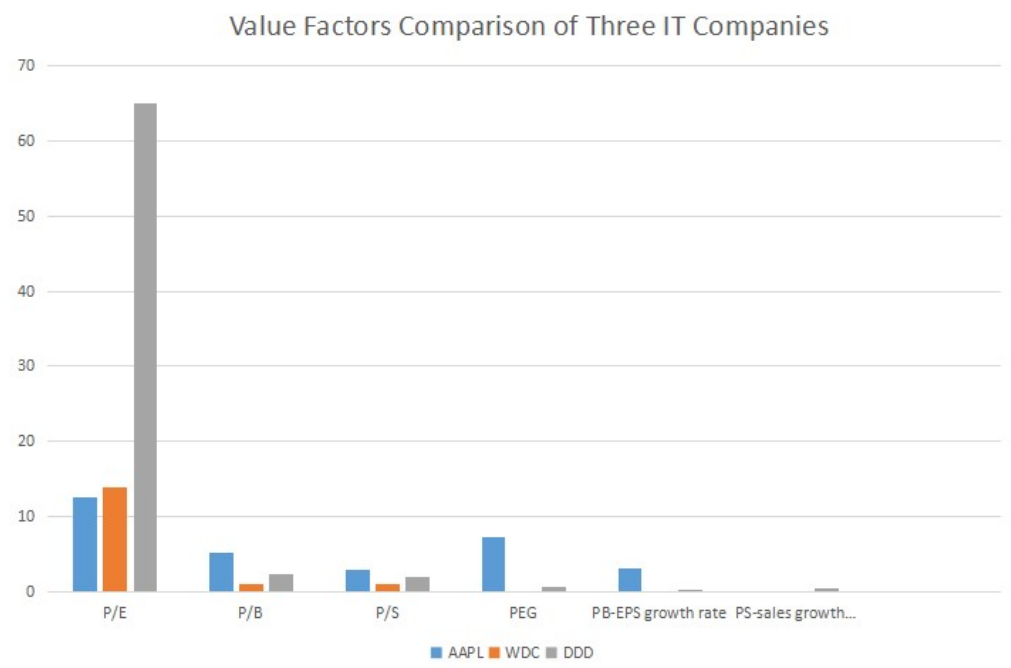

Figure 3. The cross-sectional value of three IT companies in 2018

As shown in Figure 3, the AAPL and WDC stocks with low value factors mean investment value in short term and DDD with high PE suggests a high possibility of overvalued, despite low PB and PS scores. When turning to the value-growth rate ratio, the WDC with low value factor is calculated out all negative value-growth ratio scores transmit sighs of unsustainable low value factor and short operation as an investment strategy. For DDD, those ratios are all in the normal range, showing promising growth capability but high market expectations. On the contrary, the AAPL performed best in three stocks based on six indicators. Specifically, low value factors can predict crosssectional stock return when taking holding strategy. The figure of PEG was greater than 1 cannot be seen as overvalued because Apple Inc. has developed to a stable period with inevitable characteristic of insufficient growth and no longer suitable for the PEG method. Similarly, the minus PS-sales growth can be ignored too. To conclude, the stock of Apple Inc. is valuable to invest in terms of six important indicators.

\subsubsection{Financial criteria}

The Taiwan Stock Exchange categorized 15 financial ratios from five dimensions for the sample stock and financial summary report, which has been published in the open Market Observation Post System (MOPS) [10]. Some of them are taken as input variables to measure the financial status of 
the company, as the following MOPS. In order to replace some of the original ratios with those of a similar growth tendency of profitability and operational performance, this article also includes some new ratios based on factor selection principle and IT high-tech enterprise value determinants: the growth rates of revenue, gross profit, net profit after tax, total asset, and return on asset (ROA), respectively. The dimension division and definition of each financial attribute are shown in Table 2.

Table 2 Cross-sectional financial criteria of Apple Inc.

\begin{tabular}{|c|c|c|c|c|}
\hline Dimension & Financial Indicators & Definition & $\begin{array}{c}\text { Score } \\
(\%)\end{array}$ & $\begin{array}{l}\text { Standard } \\
\text { Value } \\
(\%) \\
\end{array}$ \\
\hline \multirow{4}{*}{$\begin{array}{l}\text { Profitability } \\
\text { (P) }\end{array}$} & Return on asset (ROA) & Net profit before tax/average total asset & 19.93 & 8 \\
\hline & $\begin{array}{l}\text { Operational gross profit } \\
\text { (Ogross profit) }\end{array}$ & Operational gross profit/total revenue & 15.04 & 15 \\
\hline & Operational profit & Operational profit/total revenue & 6.74 & - \\
\hline & Net profit after tax & Net profit after tax/total revenue & 22.41 & 10 \\
\hline \multirow{2}{*}{$\begin{array}{l}\text { Liquidity } \\
\text { (L) }\end{array}$} & Quick ratio & (Current asset - Inventory)/current liability & 49.26 & 100 \\
\hline & Liquidity ratio & Current asset/current liability & 50.79 & 200 \\
\hline \multirow[t]{5}{*}{$\begin{array}{l}\text { Growth } \\
\text { (G) }\end{array}$} & $\begin{array}{l}\text { Net profit after tax } \\
\text { growth rate }\end{array}$ & $\begin{array}{c}\text { Net profit after tax } \\
\text { - previous net profit after tax) } \\
\text { /previous net profit after tax) }\end{array}$ & 23.12 & 30 \\
\hline & ROA growth rate & (ROA - previous ROA)/previous ROA & 16.74 & - \\
\hline & Total assets growth rate & $\begin{array}{c}\text { (Total asset - previous total asset) } \\
\text { /previous total asset }\end{array}$ & -2.56 & - \\
\hline & Gross profit growth rate & $\begin{array}{l}\text { (Gross profit - previous gross profit) } \\
\text { /previous gross profit }\end{array}$ & 15.48 & - \\
\hline & Revenue growth rate & $\begin{array}{l}\text { (Total revenue - previous total revenue) } \\
\text { /previous total revenue }\end{array}$ & 15.86 & - \\
\hline \multirow{2}{*}{$\begin{array}{l}\text { Solvency } \\
\text { (S) }\end{array}$} & Debt ratio & Total debt/total asset & 70.71 & 70 \\
\hline & Interest coverage ratio & $\begin{array}{l}\text { (Net profit before tax }+ \text { interest expense) } \\
\text { /interest expense }\end{array}$ & 2343.58 & 250 \\
\hline \multirow{2}{*}{$\begin{array}{l}\text { Operational } \\
\text { Efficiency } \\
\text { (OE) }\end{array}$} & Asset turnover rate & Total revenue/total asset & 72.62 & 80 \\
\hline & Inventory turnover rate & Total operational cost/average inventory & 782.13 & 300 \\
\hline
\end{tabular}

The profitability is analyzed in the following part of this section. As the vital financial ratio, the ROA reflects the return on investment of the company owner's equity. The calculated index value is $55 \%$, which is above the standard value means effective utilization of the Apple Inc. assets, increasing revenue and saving funds. Then, the difference between the ogross profit and the standard value is extremely small, indicating stable profit for Apple Inc. Besides, the operating profit of 0.6 indicates that the major operating profit provided by Apple Inc.'s commodity sales, strong profitability, and promising business conditions. The net profit after tax above 0.1 suggests high income level of sales revenue. For the growth of Apple Inc., it can be seen from the Table 2 that almost all indicators are lower than the standard value is identical with high value-growth rate ratio analyzed above, demonstrating the mature development period for the company.

Liquidity is the ability to generate cash depends on how many liquid assets can be converted into cash in time. Specifically, the quick ratio and the liquidity ratio calculated all below the normal value could be considered as low short-term solvency and greater short-term debt repayment risk for Apple Inc. Solvency refers to the ability of long-term debt repayment and risk resistance, different from the liquidity. In detail, the debt ratio extremely close to the standard value means reasonable and stable development for Apple Inc., that is, adequate funds for operation. The interest coverage ratio is much greater than 2.5 suggests the Apple Inc. has powerful ability to pay interest to avoid debt repayment risks and strong financing capability.

Operational efficiency reflects the effectiveness of assets exploit and the turnover of funds. Specifically, the asset turnover rate evaluates the quality of total asset management and the efficiency of asset utilization is around the standard value of 0.8 , showing out the fact that turnover rate of total assets and the sales ability are at a normal level. The inventory turnover rate reflects the inventory management level is higher than the standard level, suggesting the low inventory occupancy and the feasible conversion ability from inventory into cash or accounts receivable in the 
long run. The result is not contradictory with that from quick ratio and it can be revealed that the inventory can be the main solution when liabilities arise.

\subsubsection{Cross-Section Result}

In summary, Apple Inc. performed better in six value factors compared to that of WDC and DDD, especially relative low value indicator. The high value-growth rate ratio and financial criteria linking with growth reveal that the Apple Inc. is in a mature and stable development period with sufficient working capital, high asset management level, stable profitability and high long-term solvency through inventory compensation, despite the poor short-term liquidity and greater shortterm debt repayment risk. Therefore, I recommend Apple Inc. to be a candidate for investment from the perspective of cross-section.

\section{Time-series results}

The PE ratio plays a pivotal role in value investment. Thus, the time-series researches are documented for the determination of future performance. Given the limitations of static features of PE ratio when conducting cross-section analysis, the calculation of EPS, free cash flow, and close price in time-series and comparable analysis from 2016 to 2018 are conducted in order to determine the future performance of $\mathrm{PE}$ ratio.
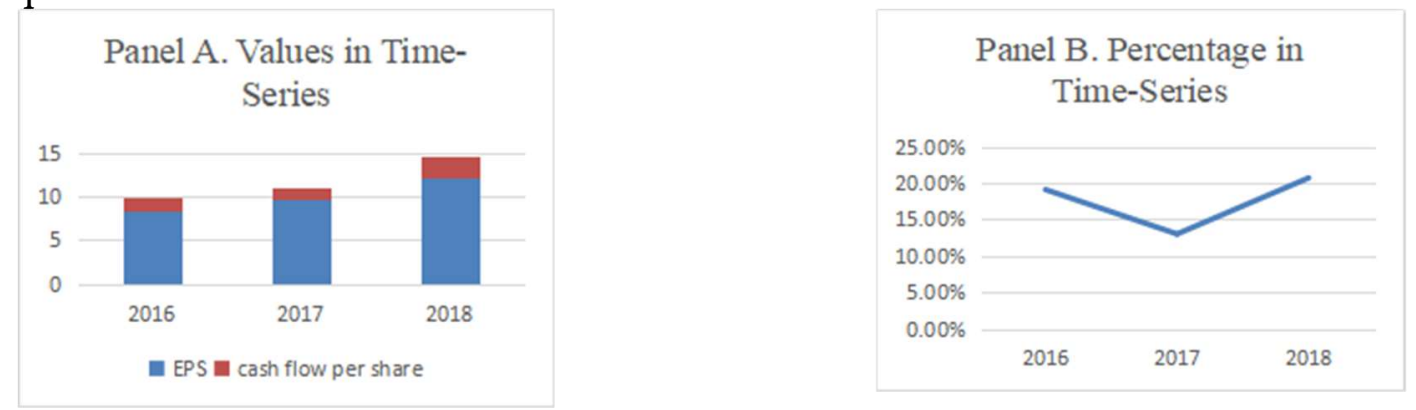

Figure 4 Panel A. The cross-sectional values of EPS and cash flow per share in three years; Panel B. The proportions of free cash flow per share to EPS in time-series. All data are retrieved from the annual financial reports in www.sec.gov.

In Figure 4, it is evident that all the free cash flows in three years are lower than EPS in timeseries. The result of the poor performance of cash flow per share for several consecutive years means the company's tight operating funds in the future, and there is not much increase in liabilities based on financial information, so it can be predicted that EPS will decline slightly in short term, consistent with the forecast by Estimize. Moreover, in the case where EPS is higher than the cash flow per share can send a signal that the profits generated from the current sales of the company mainly came from book profits to a certain extent and that there is no real cash for the company in the current period, indicating low quality of the profit and EPS with fallacious prosperity. The accounts receivable in the balance sheet increased from 2016 to 2018 and the growth rate calculated was relatively high, means that the company's sales return rate was slow and that the charge was not taken in time after the goods sold; however, the inventory decreased compared with previous years, indicating no inventory backlog. The raw material purchased back has been produced into products in short term for sales. Besides, the proportion of free cash flow per share in the past three years increased slightly in Panel B, which cannot erase the fact of still less than $25 \%$, and further confirms the poor profit performance in the future. 


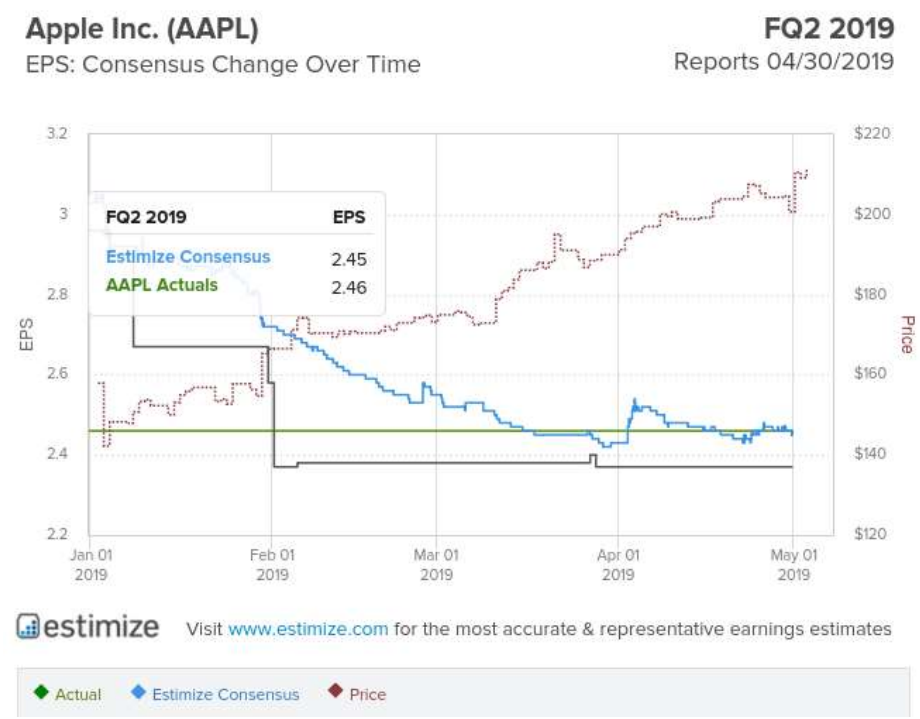

Figure 5 The data consist of monthly EPS actual and estimized value and close price of the Apple Inc. stock for the period from December 2018 to March 2019. The trend figure is shown in www.estimize.com.

The investors should pursue smaller cross-section PE in order to obtain higher stock returns. However, it is clear on the basis of Figure 5 that the actual value of PE ratio will keep around 2.45, in consistent with the result determined by esitimized consensus of 2.4 and Wall Street consensus of 2.35, respectively. However, the close price is steadily increasing, indicating durable growing market expectation, and can lead to overvalued stock for optimistic investors. Based on close price and EPS trend analysis in time-series for the recent three years, the short strategy can be conducted in long-term investment. The holding periods need to be further analyzed, the dynamic investment model can also be constructed by using computer technology and excess return can be determined by applying historical data in a backtesting system, which is the direction of the future work.

\section{Conclusion}

For the purpose of excess stock return and lower investment risk, a cross-section from different financial dimensions, the perspective of value investment, and time-series in PE are analyzed for evaluating the company's performance. In this study, I took Apple Inc. as a sample to conduct a case study that focuses on investment. I highlighted the mean reversion of value factors of Apple Inc. and further decomposed $\mathrm{PE}$ ratio to determine the profit composition with particular reference to more value factors. The value factors and financial criteria have been analyzed in the crosssection. Specifically, six value factors compassing value indicators and value-growth rate ratios are used for comparison among three IT companies, and come to the conclusion of value stock of APPL to hold in short term. Furthermore, more financial criterias have been calculated to evaluate the fundamental information of Apple Inc. with the result of stable profitability, low growth and liquidity, and strong solvency. With respect to the issues mentioned above, this article gives the recommendation of holding strategy in short term.

In the time-series, the result obtained from the trend analysis is that the proportion of the cash flow per share to EPS is keeping steady around $22 \%$, indicating low fiscal liquidity of the company. Besides, the performance of PE with stable EPS in the future may be relatively high ascribing to excessive market expectation, considering the advice of short strategy in the long run.

\section{References}

[1] E. Fama and K. French, The cross-section of expected stock returns, The Journal of Finance, vol.47, pp. 427-465, 1992

[2] J. S. Abarbanell and B. J. Bushee, Fundamental analysis, future earnings, and stock prices, Journal of Accounting Research, vol.35, pp. 1-24, 1997 
[3] A. C. Chui and K. J. Wei, Book-to-market, firm size, and the turn-of-the-year effect: evidence from Pacific-Basin emerging markets, Pacific-Basin Finance Journal, vol.6, pp. 275-293, 1998

[4] H. Wang, et al., Accounting investment value index and stock returns-empirical evidence from a-share market, China Soft Science, vol.6, pp. 102-112, 2012

[5] B. Lev and S. R. Thiagarajan, Fundamental information analysis, Journal of Accounting Research, vol.31, pp. 190, 1993

[6] L. Ii and X. Xiaoyue, The ability of financial basic information of Chinese listed companies to predict future returns, Economic Science, vol.23, pp. 53-62, 2015

[7] Y. Hui and W. Tingting, Empirical research on value investment strategy considering fundamental and valuation indicators__experience data from China's Shanghai and Shenzhen a-share markets from 2000 to 2013, Investment Research, vol.11, pp. 123-138, 2014

[8] U. W. Kok, J. Ribando and R. Sloan, Facts about formulaic value investing, Financial Analysts Journal, vol.73, pp. 81-99, 2017

[9] K. Daniel and S. Titman, Market reactions to tangible and intangible information, Journal of Finance, vol.61, pp. 1605-1643, 2006

[10]MOPS Ibsite address, Retrieved from http://emops.twse.com.tw/emops_all.htm, 2012 